\title{
Nano-ridge fabrication by local oxidation of silicon edges with silicon nitride as a mask
}

\author{
Jeroen Haneveld, Erwin Berenschot, Pascale Maury \\ and Henri Jansen \\ MESA+ Research Institute, University of Twente, PO Box 217, 7500 AE Enschede, \\ The Netherlands \\ E-mail: j.haneveld@utwente.nl
}

Received 25 November 2005, in final form 9 February 2006

Published 8 May 2006

Online at stacks.iop.org/JMM/16/S24

\begin{abstract}
A method to fabricate nano-ridges over a full wafer is presented. The fabrication method uses local oxidation of silicon, with silicon nitride as a mask, and wet anisotropic etching of silicon. The realized structures are $7-20 \mathrm{~nm}$ wide, $40-100 \mathrm{~nm}$ high and centimeters long. All dimensions are easily adjustable by varying the oxidation time, the wet etching time and the mask geometry, respectively. As an additional advantage, the method features a spatial frequency doubling effect. This can be helpful in realizing higher feature densities than would be possible using conventional lithography.
\end{abstract}

(Some figures in this article are in colour only in the electronic version)

\section{Introduction}

Currently, several tools are available to create patterns having a width in the nanometer range. These patterns are useful as imprint stamps to define 2D nanostructures in e.g. a polymer layer [1]. In this way, one master mold can be used for fast and easy replication of a large series of structures. People have used electron beam lithography to write structures in PMMA (polymethyl methacrylate) [2], focused ion beam (FIB) for direct milling of the substrate [3] or atomic force microscope (AFM) writing techniques $[4,5]$. However, these techniques have one main drawback in common: they are writing techniques. Wafer-scale writing of nanopatterns is a time- (and thus money-) consuming activity, if not impossible altogether.

A method to fabricate ridges with a width in the nanometer range, and variable height, is proposed here. The processing will be done using common optical photolithography and wet etching techniques. An additional feature of the proposed technique is the ability to double the density of lines when a periodical pattern is desired. This is an inherent property of the so-called edge or contour lithography processes [6-8].

\section{Experimental details}

In the proposed process $100 \mathrm{~mm}$, double side polished, p-type $\langle 110\rangle$ silicon wafers $(5-10 \Omega \mathrm{cm})$ were used. After an introductory standard cleaning step (10 min fuming $\mathrm{HNO}_{3}$, followed by 10 min boiling $\mathrm{HNO}_{3}$ ) and native oxide removal in $1 \% \mathrm{HF}$, a very thin $(8-15 \mathrm{~nm})$ low stress low pressure chemical vapor deposition $\mathrm{SiN}_{x}$ silicon-rich nitride layer was deposited on the wafers, followed directly by deposition of a thin (40-100 nm) TEOS (tetraethoxysilane) oxide layer (figure 1(a)). Then, a layer of positive photoresist (Olin $907 / 12$ ) was spin coated and optically exposed using a mask containing $4 \mu \mathrm{m}$ wide grating lines. The resist was developed using Olin OPD 4262 resist developer (Arch Chemicals, containing $2.5 \%$ tetramethylammonium hydroxide (TMAH) and a number of surfactants). After a postbake of $30 \mathrm{~min}$ at $120{ }^{\circ} \mathrm{C}$, the resist line pattern was transferred to the TEOS layer by etching in $1 \%$ hydrofluoric acid (HF) or buffered hydrofluoric acid (BHF). The etch time was $60 \mathrm{~s}$ in BHF for the $100 \mathrm{~nm}$ TEOS layer (etch rate $\approx 180 \mathrm{~nm} \mathrm{~min}^{-1}$ ), or $150 \mathrm{~s} \mathrm{in}$ $1 \% \mathrm{HF}$ for the $40 \mathrm{~nm}$ TEOS layer (etch rate $\approx 33 \mathrm{~nm} \mathrm{~min}^{-1}$ ). A visual etch stop was not possible, because the underlying silicon nitride layer is hydrophilic, just as the oxide layer. For this reason, a rather generous overetch (approximately 100\% 
(a)

(b)
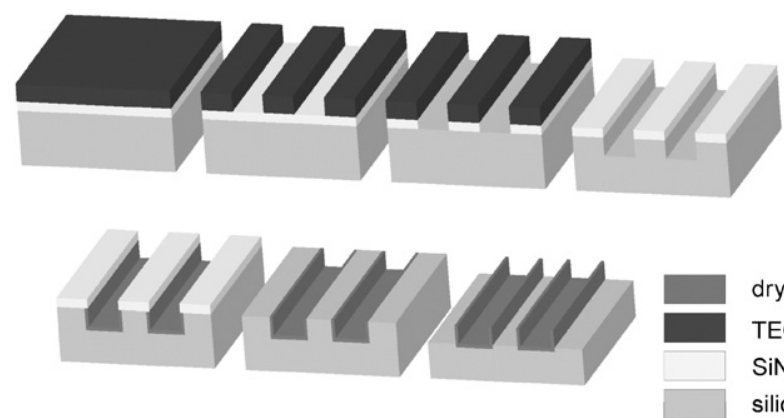

dryox

TEOS

$\mathrm{SiN}_{x}$

silicon

(e)

$(f)$

$(g)$

Figure 1. Basic process flow for nano-ridge fabrication (note the doubling of the spatial frequency of the lines).

in time) was applied to be sure to actually reach the nitride layer underneath.

After the pattern transfer into the TEOS layer, the photoresist was stripped in fuming nitric acid for $20 \mathrm{~min}$, and the wafers received a standard $\mathrm{HNO}_{3}$ cleaning step (figure 1(b)).

Subsequently, the TEOS oxide pattern was transferred to the silicon nitride layer by means of etching in hot phosphoric acid $\left(85 \% \mathrm{H}_{3} \mathrm{PO}_{4}\right.$ at $180{ }^{\circ} \mathrm{C}$ ) (figure $\left.1(c)\right)$. Then, the TEOS layer was stripped in $\mathrm{BHF}$ or $1 \% \mathrm{HF}$, directly followed by ultra low-speed wet anisotropic etching of the exposed $\langle 110\rangle$ silicon areas in OPD 4262 developer, figure $1(d)$. This developer contains $2.5 \%$ TMAH, as well as a number of surfactants, and etches $\langle 110\rangle$ silicon at a rate of $3.7 \mathrm{~nm}$ $\mathrm{min}^{-1}$ at room temperature. The bottoms and sidewalls of the resulting channels have a very low surface roughness [9].

The use of $\langle 110\rangle$-oriented silicon wafers allowed for the etching of trenches with vertical sidewalls (the slow-etching $\left\langle\begin{array}{llll}1 & 1 & 1\end{array}\right\rangle$ planes are oriented perpendicular to the wafer surface), whereas the use of a $\langle 100\rangle$ wafer would result in trenches with slanted sidewalls (at an angle of $54.7^{\circ}$ relative to the wafer surface) [10].

The silicon etch step was followed by a standard cleaning step and a $1 \%$ HF dip (to remove the oxide that has been formed during the standard cleaning). Then the wafer was dry oxidized locally at a temperature of $950{ }^{\circ} \mathrm{C}$, with the nitride mask protecting the areas of the wafer that should not be oxidized (figure 1(e)). After this so-called LOCOS process (LOCal Oxidation of Silicon [11-13]), the nitride mask was stripped in hot $\mathrm{H}_{3} \mathrm{PO}_{4}$ (figure $1(f)$ ), directly followed by another wet anisotropic silicon etch to etch back the now exposed silicon areas (figure $1(g)$ ).

The final result of the process in figure 1 is a waferscale array of oxide ridges. The width of the ridges can be defined precisely by the thickness of the dry oxide layer (and therefore by the oxidation time). The height of the ridges can be accurately tuned by adjusting the OPD 4262 silicon etching time.

As an inherent feature of the process, the period of the structures has been decreased from one line per $8 \mu \mathrm{m}$ to two ridges per $8 \mu \mathrm{m}$. This period doubling feature was also used by Ribbing et al to fabricate saw-tooth refractive x-ray lenses in $\langle 100\rangle$ silicon [14].

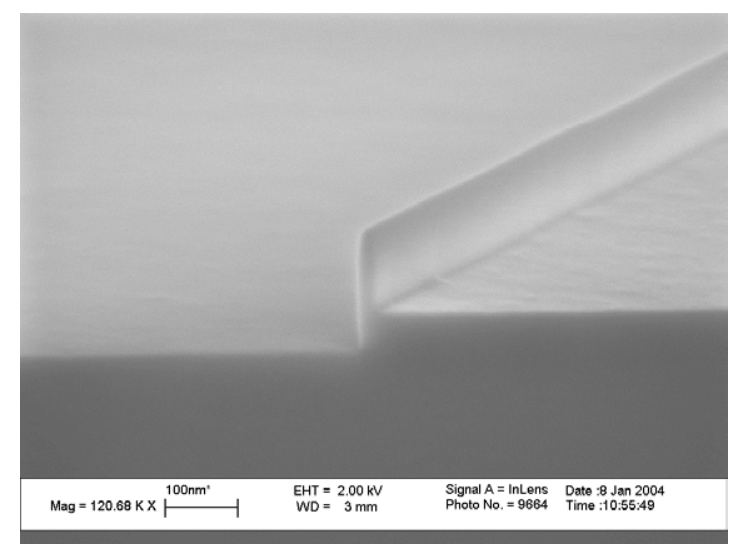

Figure 2. $20 \mathrm{~nm}$ wide nano-ridge with shorter second silicon etch step, causing a level difference.

\section{Results and discussion}

\subsection{Fabricated nano-ridge structures}

In figure 2, a nano-ridge of approximately $20 \pm 2 \mathrm{~nm}$ wide and a height of $110 \pm 10 \mathrm{~nm}$ is shown. During the fabrication of these ridges, the second silicon wet etching time (figure $1(\mathrm{~g})$ ) was intentionally chosen shorter $(30 \mathrm{~min})$ than the first silicon wet etching time (figure $1(d)$ ), which was $45 \mathrm{~min}$. This led to a clear difference in height left and right of the ridge.

In figure 3 , the ridges of approximately $15 \pm 2$ and $7 \pm$ $2 \mathrm{~nm}$ wide can be seen. For the structures in these figures, the two silicon etching steps were equally long (10 min each), leading to a height of the ridges of $38 \pm 4 \mathrm{~nm}$, as measured with a Digital Instruments NanoScope III AFM (operated in the tapping mode, scan size $10 \times 10 \mu \mathrm{m}, 512 \times 512$ data points, at a scanning frequency of $2 \mathrm{~Hz}$ ).

The final width of the nano-ridges was estimated from the thickness of the dry oxide layer after the final silicon etch step (using ellipsometry). This thickness is slightly less than the thickness of the original oxide thickness, because the etch rate of silicon dioxide in hot $\mathrm{H}_{3} \mathrm{PO}_{4}$ is not zero, as will be discussed later.

AFM scans of one of the fabricated structures with a ridge width of $15 \mathrm{~nm}$ can be found in figure 4, proving the excellent uniformity. A slight level difference can be seen in these AFM scans: this is due to the fact that the dry oxide layer grows out of the silicon surface during the local oxidation.

The twisting of the oxide ridges, observed in figure 3 , was caused by imperfections in the mask used for optical lithography. The mask quality can be improved, but it is not an issue for the current study of the fabrication aspects of the stamps. In all the cases, hardly any defects could be found on full wafer scale.

\subsection{Etching selectivity of $\mathrm{SiO}_{2} / \mathrm{SiN}_{x}$ in $\mathrm{H}_{3} \mathrm{PO}_{4}$}

Based on the SEM pictures and on thickness measurements of the dry oxide layer before and after stripping of the nitride layer, the nano-ridges were observed to be a little less wide than the initial thickness of the grown dry oxide layer. This is due to the fact that not only the silicon was oxidized in the LOCOS step, but also the $\mathrm{SiN}_{x}$ mask was oxidized, if only a 


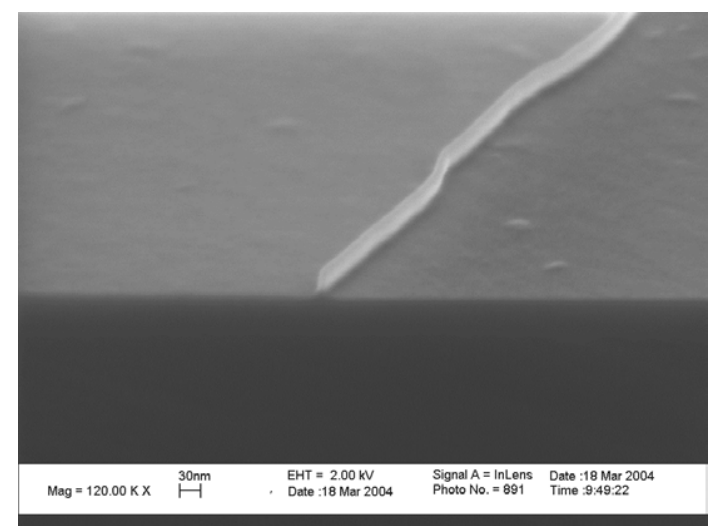

(a)

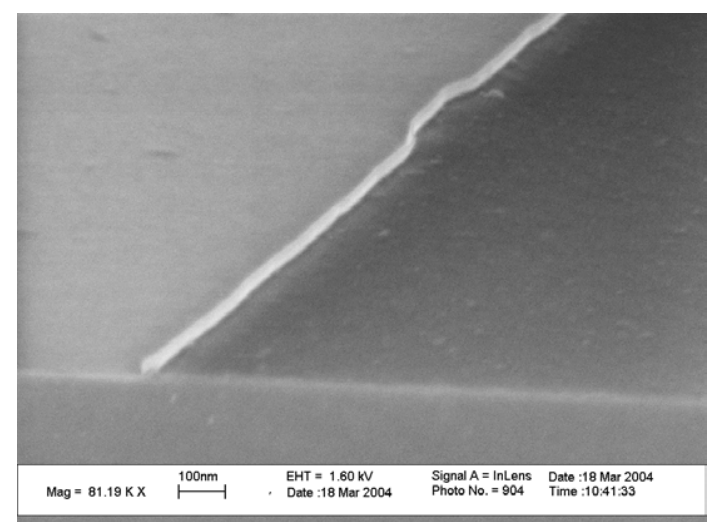

(b)

Figure 3. (a) $15 \mathrm{~nm}$ wide nano-ridge with two identical silicon etch steps. (b) $7 \mathrm{~nm}$ wide nano-ridge with two identical silicon etch steps.

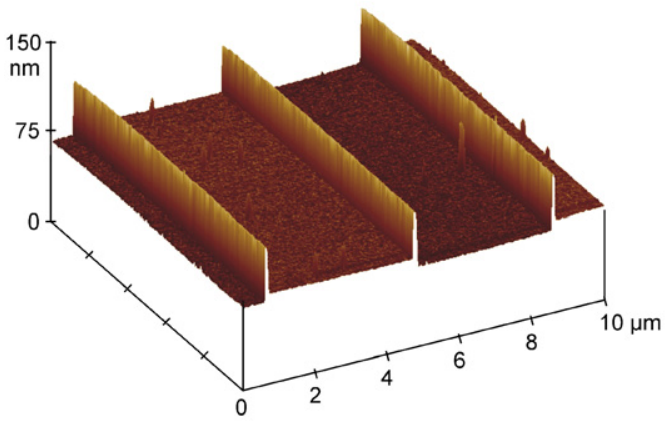

(a)

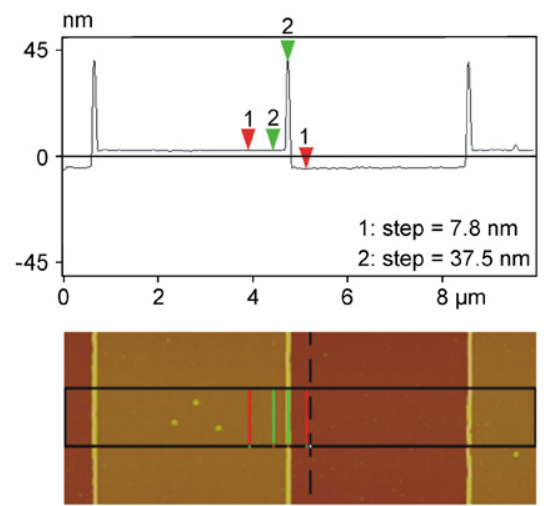

(b)

Figure 4. AFM scans of $15 \mathrm{~nm}$ wide nano-ridges. (a) 3D view of the fabricated structures. (b) Section view with height measurements. The width of the edges cannot be accurately determined with AFM, due to the fact that an AFM picture is actually a convolution of the sample with the AFM tip, which has a limited radius $(10 \mathrm{~nm})$ and a finite aspect ratio $(3: 1)$.

little bit $[13,15]$. When stripping the $\operatorname{SiN}_{x}$ in step $(f)$ (see figure 1), this led to a longer stripping time in $\mathrm{H}_{3} \mathrm{PO}_{4}$ than the time that was initially needed to etch the nitride mask in step $(c)$ (because the $\mathrm{H}_{3} \mathrm{PO}_{4}$ had to break through the thin oxide covering the $\mathrm{SiN}_{x}$ layer before the bulk $\mathrm{SiN}_{x}$ could be etched). During this longer etch, also the dry oxide was exposed for a longer period to the phosphoric acid. This led to a loss of 6 $\pm 1 \mathrm{~nm}$ of the dry oxide in these experiments (as measured with a Plasmos SD 2002 ellipsometer). To try to improve the selectivity of $\mathrm{SiN}_{x}$ over $\mathrm{SiO}_{2}$, a comparison between the etch rates of these materials in hot phosphoric acid was performed, (because this selectivity has been observed to improve when lowering the temperature of the $\mathrm{H}_{3} \mathrm{PO}_{4}[16]$ ).

The results of this experiment (table 1) show that lowering the temperature had no significant effect on the selectivity in our case. However, the absolute silicon dioxide and silicon nitride etch rates dropped significantly (approximately a factor of 3 for each $20^{\circ} \mathrm{C}$ of temperature difference), but for our purpose this was not useful. An option would be to use a nitride that oxidizes slower at $950{ }^{\circ} \mathrm{C}$, for example stoichiometric $\mathrm{Si}_{3} \mathrm{~N}_{4}$ [13]. This could also have consequences for the selectivity of nitride/oxide. However, this option has not been explored, because the current selectivity (approximately 9:1) was enough to demonstrate the proof of principle of the technology.
Table 1. Influence of temperature on etch rates of $\mathrm{SiN}_{x}$ and $\mathrm{SiO}_{2}$ in hot phosphoric acid.

\begin{tabular}{llll}
\hline $\begin{array}{l}\text { Temperature } \\
\left({ }^{\circ} \mathrm{C}\right)\end{array}$ & $\begin{array}{l}\text { Etch rate } \mathrm{SiN}_{x} \\
\left.(\mathrm{~nm} \mathrm{~min})^{-1}\right)\end{array}$ & $\begin{array}{l}\text { Etch rate } \mathrm{SiO}_{2} \\
\left(\mathrm{~nm} \mathrm{~min}^{-1}\right)\end{array}$ & $\begin{array}{l}\text { Selectivity } \\
(-)\end{array}$ \\
\hline 180 & 4.1 & 0.48 & $8.5: 1$ \\
160 & 1.4 & 0.16 & $8.9: 1$ \\
140 & 0.5 & 0.05 & $8.6: 1$ \\
\hline
\end{tabular}

\subsection{Nano imprint lithography using nano-ridges as a stamp}

Imprints of the nanostructures were made using hot embossing in PMMA (the glass temperature $T_{\text {glass }}$ of PMMA is $105{ }^{\circ} \mathrm{C}$ ). Before imprinting, the stamps were coated with an antisticking layer (a self-assembled monolayer of $1 H, 1 H, 2 H, 2 H$-perfluorodecyl-trichlorosilane; gas phase deposition in a desiccator under vacuum). The imprinting temperature was $180{ }^{\circ} \mathrm{C}$ ( 2 min heating up), the imprint pressure was 40 bar and the cooling down time was around $20 \mathrm{~min}$. The samples were separated at a temperature of approximately $108^{\circ} \mathrm{C}$ (just above the glass temperature of the PMMA). Any residue of PMMA in the imprinted slits can be removed in an $\mathrm{O}_{2}$ plasma etch step.

Figure 5(a) shows an AFM scan of the PMMA layer after imprinting with the $20 \mathrm{~nm}$ wide, 'two-level' nano-ridges 


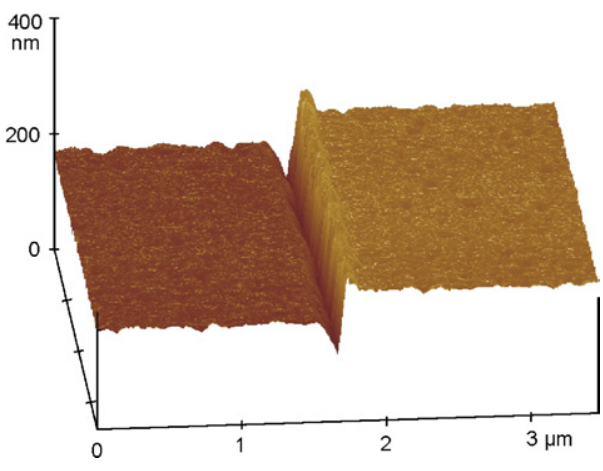

(a)

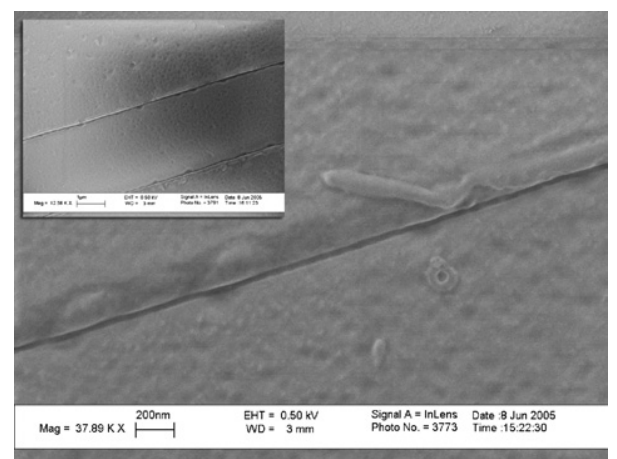

(b)

Figure 5. Imprints of $20 \mathrm{~nm}$ wide nano-ridges in PMMA. (a) AFM image of the imprinted layer (note the level difference). (b) SEM picture of the imprinted PMMA layer (inset: lower magnification view).

from figure 2. It is difficult to say anything about the dimensions of the imprinted structure based on the AFM picture, due to AFM tip convolution effects. However, the level difference as measured by AFM was $51 \pm 5 \mathrm{~nm}$, and this is in good agreement with our calculations (based on the unequal silicon etching steps) and with the SEM picture in figure 2. Figure 5(b) shows a SEM image of the imprinted PMMA layer: a detailed inspection of close-ups showed that the trench width is in fact in the order of $20-40 \mathrm{~nm}$.

\subsection{Possible extensions of this technology}

In the present case, the combination of anisotropic wet etching and the crystal orientation of the $\langle 110\rangle$ wafers limits us to straight trenches with vertical sidewalls in the $\left\langle\begin{array}{llll}1 & 1 & 0\end{array}\right\rangle$ direction only. On a $\langle 110\rangle$ wafer, only two orientations of the mask give channels with vertical sidewalls: parallel to the primary or the secondary flat of the wafer. When arbitrary shaped structures are desired, reactive ion etching (RIE) could be used to transfer the pattern into the silicon substrate (instead of wet anisotropic etching). RIE is able to produce arbitrary shaped structures with near-vertical sidewalls. Nevertheless, they are usually slightly tapered and not as smooth as the walls obtained by wet anisotropic OPD etching, leading to a less well-defined geometry of the final structure. An example of such a technology can be found in [8].

\section{Conclusions}

We have successfully fabricated silicon oxide nano-ridges, based on standard optical photolithography and wet etching techniques. Wafer-scale structures, with a variable width and height in the sub-50 nanometer range, were produced. Linewidths ranging from 7 to $20 \mathrm{~nm}$ have been obtained, while the height can be varied from around $20 \mathrm{~nm}$ to a few hundred nanometers. The process delivers defect-free structures over a large area, and can be adapted using RIE to comprise various geometries, by modifying the photolithography mask design to suit specific needs.

\section{Acknowledgments}

Mark Smithers is acknowledged for his help in making the SEM pictures. This project is financed by the
Dutch technology foundation STW (project 5554), which is financially supported by The Netherlands Organization for Scientific Research (NWO) and the Dutch Ministry of Economic Affairs.

\section{References}

[1] Yu Z N and Chou S Y 2004 Triangular profile imprint molds in nanograting fabrication Nano Lett. 4 341-4

[2] Fischer P B, Dai K, Chen E and Chou S Y 199310 Nm Si pillars fabricated using electron-beam lithography, reactive ion etching, and Hf etching J. Vac. Sci. Technol. B $112524-7$

[3] Campbell L C, Wilkinson M J, Manz A, Camilleri P and Humphreys C J 2004 Electrophoretic manipulation of single DNA molecules in nanofabricated capillaries $L a b$ on a Chip 4 225-9

[4] Held R, Heinzel T, Studerus P, Ensslin K and Holland M 1997 Semiconductor quantum point contact fabricated by lithography with an atomic force microscope Appl. Phys. Lett. 71 2689-91

[5] Wendel M, Lorenz H and Kotthaus J P 1995 Sharpened electron beam deposited tips for high resolution atomic force microscope lithography and imaging Appl. Phys. Lett. $673732-4$

[6] Chung K H, Choi W Y, Sung S K, Kim D H, Lee J D and Park B G 2003 Pattern multiplication method and the uniformity of nanoscale multiple lines J. Vac. Sci. Technol. B 21 1491-5

[7] Tas N R, Berenschot J W, Mela P, Jansen H V, Elwenspoek M and van den Berg A 2002 2D-confined nanochannels fabricated by conventional micromachining Nano Lett. 2 1031-2

[8] Yan X M, Kwon S, Contreras A M, Bokor J and Somorjai G A 2005 Fabrication of large number density platinum nanowire arrays by size reduction lithography and nanoimprint lithography Nano Lett. 5 745-8

[9] Haneveld J, Jansen H, Berenschot E, Tas N and Elwenspoek M 2003 Wet anisotropic etching for fluidic 1D nanochannels J. Micromech. Microeng. 13 62-6

[10] Seidel H, Csepregi L, Heuberger A and Baumgaertel H 1990 Anisotropic etching of crystalline silicon in alkaline solutions: I. Orientation dependence and behavior of passivation layers J. Electrochem. Soc. 137 3612-26

[11] Appels J A, Kooi E, Paffen M M, Schatorje J J H and Verkuylen W 1970 Local oxidation of silicon and its applications in semiconductor-device technology Philips Res. Rep. 25 118-32

[12] van Zeijl H W, Nanver L K and French P J 1995 Low-stress nitride as oxidation mask for submicrometer locos isolation Electron. Lett. 31 927-9 
[13] Pereira M A, Diniz J A, Doi I and Swart J W 2003 Silicon nitride deposited by ECR-CVD at room temperature for LOCOS isolation technology Appl. Surf. Sci. 212 388-92

[14] Ribbing C, Cederstrom B and Lundqvist M 2003

Microfabrication of saw-tooth refractive x-ray lenses in low-Z materials J. Micromech. Microeng. 13 714-20
[15] Fränz I and Langheinrich W 1971 Conversion of silicon nitride into silicon dioxide through the influence of oxygen Solid-State Electron. 14 499-505

[16] van Gelder W and Hauser V E 1967 The etching of silicon nitride in phosphoric acid with silicon dioxide as a mask J. Electrochem. Soc. 114 869-72 